\title{
Chronic Constipation and Megarectum in a 14-Year-Old Patient Operated of Anorectal Malformation-Case Report
}

\author{
Sejdi Statovci, Nexhmi Hyseni, Hasan Ahmeti, Sadik Llullaku, Ardian Shefkiu, \\ Defrim Kocinaj \\ Clinic of Pediatric Surgery, University Clinical Centre of Kosovo, Prishtina, Kosovo \\ Email: sejdistatovci@yahoo.com
}

Received 8 March 2015; accepted 26 March 2015; published 30 March 2015

Copyright (C) 2015 by authors and Scientific Research Publishing Inc.

This work is licensed under the Creative Commons Attribution International License (CC BY). http://creativecommons.org/licenses/by/4.0/

(c) (i) Open Access

\begin{abstract}
The aim of this paper is to present the case of a female patient, 14 years of age, who developed a megarectum and overflow of fecal incontinence as a consequence of chronic and severe constipation, after the surgical repair of her vestibular fistula at the age one. The huge rectum was resected than dissected down to the pelvic floor and a new anus was reconstructed via a posterior sagittal anorectoplasty with excellent results.
\end{abstract}

\section{Keywords}

Vestibular Fistula, Constipation, Megarectum, Bowel Resection

\section{Introduction}

Anorectal malformations (ARM) include a wide spectrum of congenital defects of the anus, anal canal and rectum, which are often combined with urogenital tract defects and associated with other congenital anomalies. Their incidence is between 1 in 2000 and 1 in 5000 live births [1] [2]. They appear with different clinical presentation ranging from simple defects to very complex anomalies. Vestibular fistula is a defect in females where the atretic bowel ends with fistula opening into the vestibule. Posterior Sagittal anorectoplasty described by Alberto Pena is widely accepted as the standard technique for treatment of anorectal anomalies [3]. Despite remarkable advances in operative techniques and survival rates of these patients, there is still high occurrence of postoperative constipation and fecal incontinence, even after an excellent surgical repair. The most frequent functional disorder after treatment for ARM in which the rectum has been preserved is constipation [4]. Redo operations are a good choice for cases with chronic and resistant constipation with huge dilated rectosigmoid. 


\section{Case Report}

In this paper we present the case of a 14-year-old female patient, with severe constipation and soiling of the third grade despite regular enemas, laxatives and dietary modulation. Barium enema shows a marked dilation of the rectosigmoid portion of the large bowel (Figure 1). She had been operated on four times previously, after being born with rectovestibular fistula; surgery included the formation of a transverse loop colostomy, posterior sagittal anorectoplasty, closure of colostomy and later a cut back procedure because of anal stenosis. After the last operation, her parents did not bring her back to the control room thinking that her treatment was complete and that the complaints she had with constipation were considered "normal". So the follow up was interrupted. Occasionally attempts were made for treatment for her constipation with laxatives and diet.

On examination her lower abdomen was distended with what appeared to be a huge fecaloma on bimanual examination, which also demonstrated a cavernous rectum. She was found to have a normal sacrum, wellformed buttocks consistent with the subsequent intraoperative findings of good pelvic floor muscles. The anus appeared to not be completely closed with a weak tonus and slightly displaced anteriorly that had a constant leakage of a small amount of feces. With digito-rectal examination inside the colon, we found a large fecaloma. Plain abdominal X-ray and also barium studies showed a huge and dilated rectum, filled with massive fecaloma. It was constipation of grade 3 with an overflow fecal incontinence due to untreated chronic constipation after surgical treatment of vestibular fistula. The patient underwent several enemas, despite which she had a large amount of rectal feces on examination under anesthetic. A laparotomy, with the intention of an abdominoperineal procedure, combined with rectal resection, was commenced. The huge rectum was resected than dissected down to the pelvic floor and a new anus was reconstructed via a posterior sagittal anorectoplasty. Anorectal angle was established by suturing the muscle complex around the neo-anorectal region after the reconstruction of the perineal body (Figure 2).

Postoperative recovery was normal and without complications, including intravenous antibiotics (Figure 3). During the first two months after the operation there were several episodes of some soiling, but later the patient adapted to the new situation without constipation and managed to achieve voluntary control over her bowel movements. The patient now has the voluntary bowel movements with the ability to hold the bowel movement and she is having a normal daily bowel motion without medication. The patient is aware of the importance of a well-balanced diet, plenty with fibers and a lot of liquids, and she is very careful on avoiding the constipation. The quality of her life changed radically after the last operation.

\section{Discussion}

Posterior sagittal approach (PSARP), introduced by Alberto Pena became widely accepted as the standard approach for all types of imperforate anus. It is an operation that has been shown to give good results for the repair

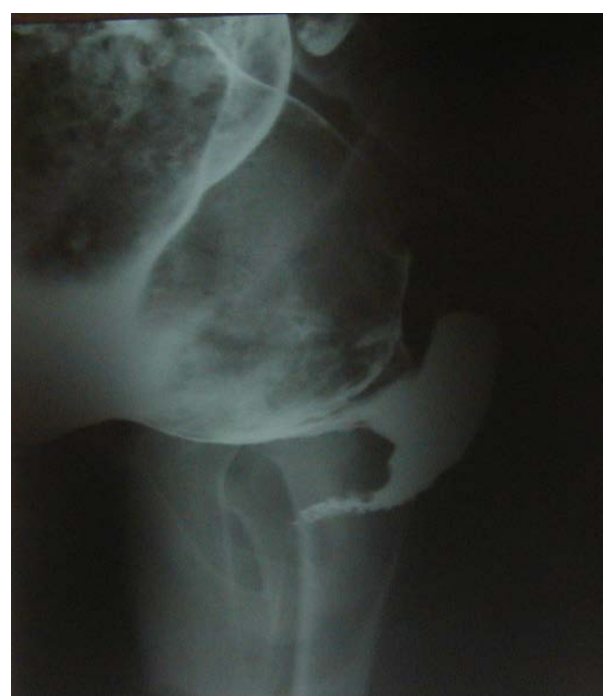

Figure 1. Barium enema (lateral view) shows a marked dilation of the rectosigmoid. 


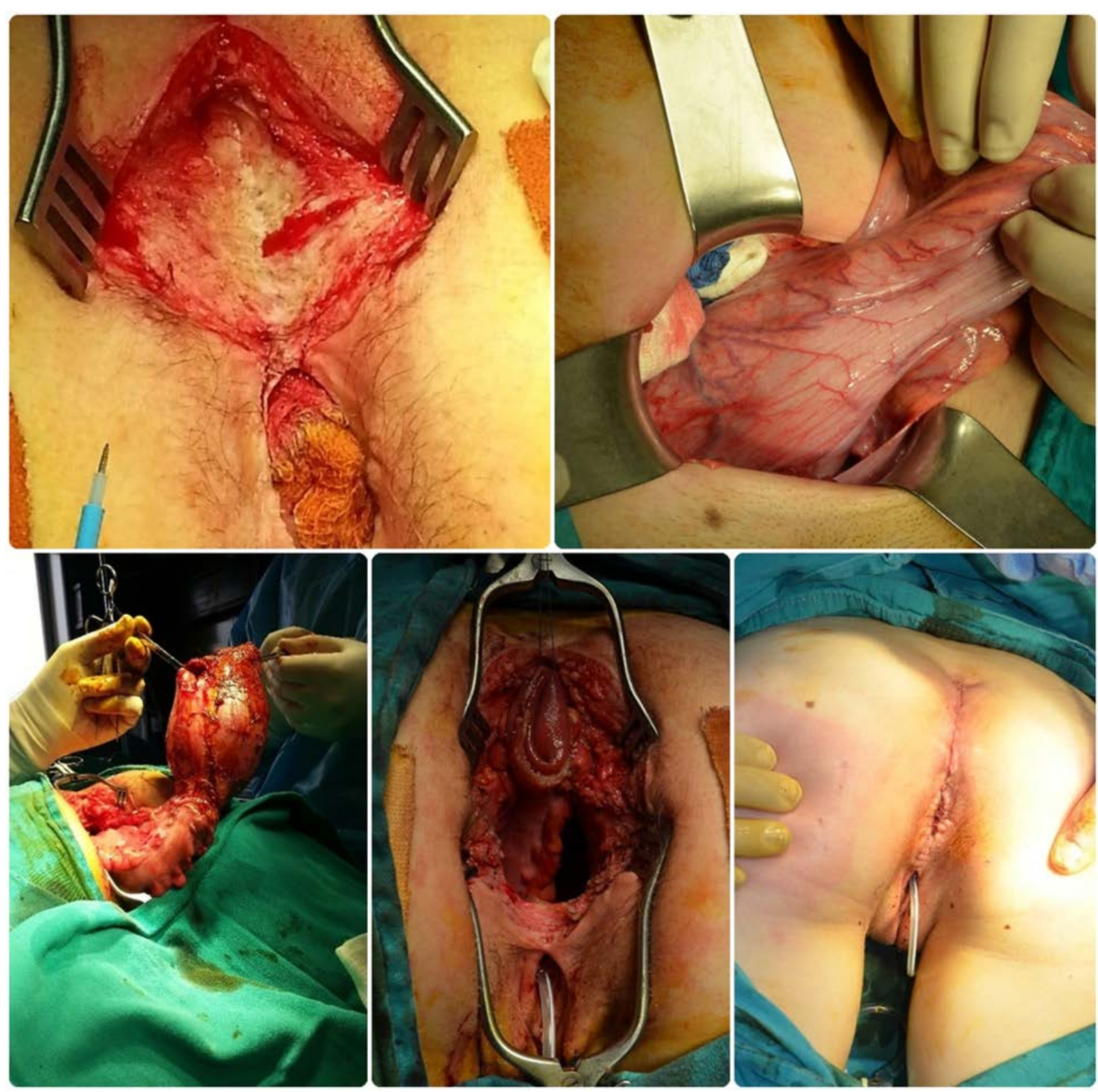

Figure 2. Different stages of abdomino-perineal approach, resection of megarectum and posterior sagittal anorectoplasty.

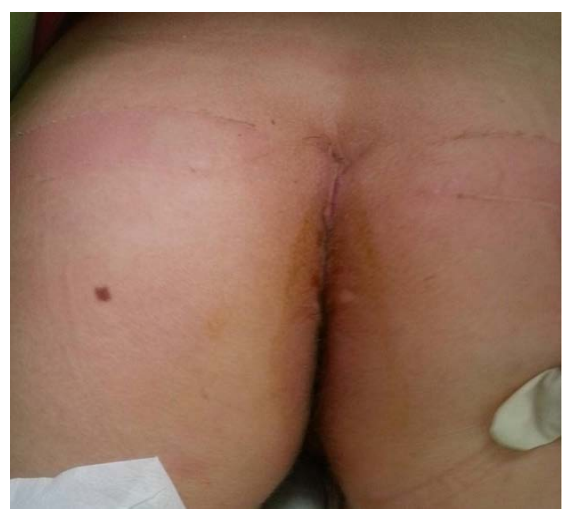

Figure 3. Day 7 after the operation. 
of anorectal malformations, achieving the maximum functional results without endangering neuromuscular innervation of the anal sphincter [5]. Although the results appear to be superior to the previous techniques, there are high incidences of postoperative fecal incontinence and constipation that occurs even after an excellent surgical repair. Females with rectovestibular fistula are among the patients who suffer more form constipation after surgery. Failure to avoid constipation can result in megarectum, and can lead to fecal impaction and overflow incontinence. According to Lewit and Pena, megarectum is more common in patients for whom a transverse or loop colostomy was performed in the newborn period [4]. The patient we are presenting in this paper fulfills this condition because loop colostomy at the level of transverse colon was performed after birth.

Redo anorectoplasty can be used to improve the outcome and has been shown in different studies [6]-[8]. However, in cases with severe and resistant constipation or incontinence after an anorectoplasty, and in whom clinical and radiological evaluation reveals a huge and dilated rectum, many pediatric surgeons have been skeptical about the redo anorectoplasty, preferring to use other techniques such as Malone appendicosotmy [9], anterior sagittal anorectoplasty [10], rectosigmoid resection [4] [11], or bowel imbrication [12]. Excision of megarectum in children who had previous repair of anorectal malformation results in fecal continence in the presence of a good internal anal sphincter and absence of neuropathy [13].

While many authors have advocated surgical resection, others propose intense bowel management, as the treatment of choice, claiming that bowel functional outcome in children with megarectosigmoid after ARM correction was similar after either surgical or conservative treatment during a follow-up. Authors of the mentioned study conclude that the radiological signs of rectal dilatation and elongation disappear after surgical intervention, but rectal dilatation and elongation also disappeared in the conservatively treated patients over time [14].

\section{Conclusion}

To conclude, unsuccessful treatment of postoperative constipation can result in megarectum, and can lead to fecal impaction and overflow incontinence. Therefore, dilatation of the rectum and sigmoid should always be considered whenever a child is having intractable constipation or fecal incontinence after repair of an anorectal malformation. Resection of the megarectum must be considered as a therapeutic alternative.

\section{Acknowledgements}

The authors would like to thank Dr. Paddy Dewan who was the main surgeon in this case and the Australian based organisation "Kind Cuts for Children", for their support and contribution to the treatment of children with anorectal anomalies and urologic anomalies in Kosovo over the past few years.

\section{Conflict of Interest}

The authors declare that there is no conflict of interests regarding the publication of this manuscript.

\section{References}

[1] Upadhyaya, V.D., Gangopadhyay, A.N., Srivastava, P., Hasan, Z. and Sharma, S.P. (2008) Evolution of Management of Anorectal Malformation through the Ages. The Internet Journal of Surgery, 17, 1.

[2] Levitt, M.A. and Peña, A. (2010) Imperforate Anus and Cloacal Malformations. Ashcraft's Pediatric Surgery. 5th Edition, Saunders Elsevier, Philadelphia, 468-490.

[3] Rintala, R.J. (1996) Anorectal Malformations-Management and Outcome. Seminars in Fetal and Neonatal Medicine, 1, 219-230

[4] Levitt, M.A. and Peña, A. (2007) Anorectal Malformations. Orphanet Journal of Rare Diseases, 2, 33 http://dx.doi.org/10.1186/1750-1172-2-33

[5] De Vries, P.A. (2001) Posterior Sagittal Anorectoplasty. Journal of Paediatric Surgery, 17, 638-643. http://dx.doi.org/10.1016/S0022-3468(82)80126-7

[6] Brain, A.J. and Kiely, E.M. (2001) Posterior Saggital Anorectoplasty for Reoperation in Children with Anorectal Malformations. British Journal of Surgery, 76, 57-59. http://dx.doi.org/10.1002/bjs.1800760117

[7] Pena, A. (2001) Posterior Saggital Anorectoplasty as a Secondary Operation for the Treatment of Faecal Incontinence. Journal of Pediatric Surgery, 18, 762-773. http://dx.doi.org/10.1016/S0022-3468(83)80020-7

[8] Dewan, P.A., Hrabovszky, Z. and Mathew, M. (2000) Redo Anorectoplasty in the Managemnt of Anorectal Anomaly 
Patients. Australian and New Zealand Journal of Surgery, 70, 109

[9] Har, A.F., Rescorla, F.J. and Croffie, J.M. (2013) Quality of Life in Pediatric Patients with Unremitting Constipation pre and Post Malone Antegrade Continence Enema (MACE) Procedure. Journal of Pediatric Surgery, 48, $1733-1737$. http://dx.doi.org/10.1016/j.jpedsurg.2013.01.045

[10] Okada, A., Tamada, H., Tsuji, H., Azuma, T., Yagi, M. and Kamata, S. (2001) Anterior Sagittal Anorectoplasty as a Redo Operation for Imperforate Anus. Journal of Pediatric Surgery, 28, 933-938. http://dx.doi.org/10.1016/0022-3468(93)90701-L

[11] Moss, R.L. (2001) The Failed Anoplasty; Successful Outcome after Reoperative Anoplasty and Sigmoid Resection. Journal of Pediatric Surgery, 33, 1145-1148. http://dx.doi.org/10.1016/S0022-3468(98)90548-6

[12] Dewan, P.A., Elsworthy, E., Mathew, M., Poki, O., Khaw, S.L., Roberts, K. and Catto-Smith, A. (2004) Bowel Imbrication in the Management of Anorectal Anomalies. Pediatric Surgery International, 20, 708-713. http://dx.doi.org/10.1007/s00383-002-0935-8

[13] Keshtgar, A.S., Ward, H.C., Richards, C. and Clayden, G.S. (2007) Outcome of Excision of Megarectum in Children with Anorectal Malformation. Journal of Pediatric Surgery, 42, 227-233. http://dx.doi.org/10.1016/j.jpedsurg.2006.09.021

[14] Borg, H., Bachelard, M. and Sillén, U. (2014) Megarectosigmoid in Children with Anorectal Malformations: Long Term Outcome after Surgical or Conservative Treatment. Journal of Pediatric Surgery, 49, 564-569. http://dx.doi.org/10.1016/j.jpedsurg.2013.08.003 